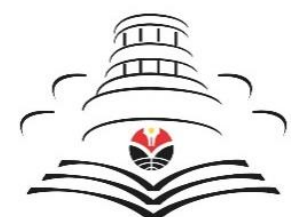

INDONESIAN JOURNAL OF APPLIED LINGUISTICS

Vol. 8 No. 3, January 2019, pp. 607-615

Available online at:

http://ejournal.upi.edu/index.php/IJAL/article/view/15260

doi: 10.17509/ijal.v8i3.15260

\title{
How language teachers perceive information and communication technology
}

\author{
Patrisius Istiarto Djiwandono \\ English Letters Department, Faculty of Language and Arts, Universitas Ma Chung, Villa Puncak Tidar N-O1, \\ Malang 65151, Indonesia
}

\begin{tabular}{|c|c|}
\hline \multirow{2}{*}{\multicolumn{2}{|c|}{$\begin{array}{l}\text { ABSTRACT } \\
\text { The digital technology has permeated almost every aspect of life. Meanwhile, the responses } \\
\text { from the field of language teaching in Indonesia to this new development have been scarce. } \\
\text { The paper aims to provide an answer to the question whether language teachers perceive } \\
\text { information and communication technology (ICT) as a threat or a helpful assistant. To achieve } \\
\text { this, a survey was conducted to } 110 \text { English teachers in Java, Indonesia. Five closed-ended } \\
\text { items and two open-ended items in an online questionnaire asked them several questions about } \\
\text { what conditions they see as threats, how they perceive ICT, and what digital facilities they have } \\
\text { been using in their work. The results show that most of them perceived ICT positively, seeing it } \\
\text { as a beneficial rather than threatening force. To them, ICT has been an attractive source that } \\
\text { provides learning resources, fosters communication and collaboration, and spices up teaching- } \\
\text { learning activities. Those who expressed their worry over ICT mentioned the importance of } \\
\text { teachers' upgrading their ICT skills and called for institutional support for the teachers. Three } \\
\text { models, TAM (technological acceptance model), UTAUT (unified theory of acceptance and use } \\
\text { of technology), and TPACK (technological pedagogical content knowledge) were then } \\
\text { discussed to address the need for helping teachers adapt to the fast-changing digital technology. } \\
\text { Keywords: Digital technology; information and communication technology; language teaching; } \\
\text { teacher's perception }\end{array}$}} \\
\hline & \\
\hline & \\
\hline $\begin{array}{l}\text { technology. Indonesian Journal of Applie } \\
\text { 10.17509/ijal.v8i3.15260 }\end{array}$ & $\begin{array}{l}\text { information and communication } \\
\text { inguistics, } 8, \quad 607-615 . \quad \text { doi: }\end{array}$ \\
\hline
\end{tabular}

\section{INTRODUCTION}

Disruption by digital technology has been increasingly pervasive in almost every aspect of life, including the field of education. Some teachers, in particular those who are hardly familiar with rapid advances of information technology and have been accustomed to using conventional methods, quite possibly begin to feel uncomfortable. As Driessen (2017, p. 1) argued, digital disruption "heralds a change that may seem particularly unwelcome to those forced to uproot their traditional ways of doing things." There is a general feeling that educational field has not responded to this development quickly enough. West (2013) argued that while digital technology has been transforming the way people read and learn, educational institutions still practice conventional teaching methods. More concrete evidence was presented by Bridglall (2018), who stated that technology disruption in the form of robotics, artificial intelligence, and machine learning will replace human workers in two thousand work activities, including natural language processing. One might wonder whether teachers are aware of this rapidly changing arena and are gearing up for major changes. A theoretical framework that is pertinent to this issue is technology acceptance model (TAM), which according to Visuvalingam (2006, p. 18) is "one of the most widely and empirically tested theories that drew on social psychological approach to explain adoption of technology and the factors that influenced individuals." Proposed by Davis et al. (cited in Visuvalingam, 2006), 
TAM sheds light on technology acceptance and describes how its end users behave toward it. Visuvalingam (2006) states that TAM is comprised of six constructs: actual system of use, behavioral intention to use, attitude toward its use, perceived usefulness, perceived ease of use, and external characteristics. The external factors prompt users to form perceived ease of use and usefulness of information technology. In turn, these latter two determine the attitude toward its use, which then promote the behavioral intention to use and finally culminate in the actual use of the technology. This theoretical framework was used in this study as a foundation for developing the instrument.

To date, there have been a handful of studies pertinent to the issue of teachers' perception on ICT. Lubis (2018) studied the perception of 13 English teachers on ICT integration into language teaching, and found that they perceived it positively. However, its benefits were still limited to technical levels rather than functional and communicative levels. Asnawi, Qismullah, and Rena (2018) studied 26 English teachers in Banda Aceh, and found that they perceived ICT as helpful in teaching. Finally, Liu, Lin, Zhang, and Zheng (2017) used a path analysis to conjecture that teachers' perception of technology could be predicted by perceived usefulness, subjective norms, and facilitating conditions.

Thus, so far the existing studies have focused on teachers' perception of ICT and the possible factors behind their perception. It is necessary to widen the scope of the research to identify other factors, in addition to the recent ICT development, that may have been perceived as helpful or threatening by language teachers. At the same time, there is paucity in studies on how foreign language teachers feel about this new development that may impact their career. It would be interesting to explore their opinions about this potentially threatening development. The paper is based on a survey that set out to identify and describe English language teachers' views on today's aspects of development that may impact their teaching profession, one of which is information and communication technology (henceforth, ICT). More specifically, it addresses the questions of (1) the things that teachers perceive as threats to their career, and (2) whether the teachers feel threatened by the versatile nature of digital technology.

\section{METHOD}

Prior to the survey, a questionnaire was designed to elicit the data. Following Brown (2001), the content validity of the questionnaire was established by submitting it to a panel of experts consisting of a senior professor in language education and two lecturers holding Doctorate degrees in applied linguistics and educational technology, respectively. Based on their opinions, what was formerly a 10 -item survey was reduced to 5-item questionnaire. The other two openended questions were later added to dig information more deeply. The 5-closed ended items asked these questions: (1) their age, (2) whether they feel threatened by increasingly numerous apps that help students learn English, (3) which conditions make them feel threatened in their career, (4) which conditions have assisted them in their teaching, and (5) which of the following statements they most agree with: (a) digital technology helps them in their work, (b) digital technology in the long run will replace them as teachers, and (c) digital technology does not have any significant impact on their career. The 2 open-ended questions asked them what apps or websites they had been using for their teaching and in what way they felt digital technology had been assisting them or threatening their careers. Repeatedsurvey reliability (Brown, 2001) was conducted by having a group of colleagues answer the questionnaire on two different dates. The correlation coefficient of 0.891 was obtained between the scores of the two different dates, indicating sufficient reliability.

The questionnaires were then presented as a Google Form and sent to 110 English lecturers and teachers in Java, Indonesia. They were selected randomly from an accessible population of 773 lecturers.

\section{FINDINGS AND DISCUSSION}

The following section presents the findings of the study. Overall, the respondents perceived ICT as helpful but also mentioned other issues that they felt were potentially impactful upon their career. Table 1 shows the age profile of the respondents.

\begin{tabular}{cl} 
Table 1. Age range of the respondents $(\mathrm{N}=110)$ \\
\cline { 2 - 2 } Age range & \multicolumn{1}{c}{ Percentage } \\
\hline $31-40$ years old & 32.7 \\
$41-50$ years old & 29.1 \\
$20-30$ years old & 20 \\
$51-60$ years old & 16.4 \\
60 and above & 1.8 \\
\hline
\end{tabular}

As Table 1 shows, half of the respondents (around $52 \%$, comprising those aged between 20 to 30 and 31 to 40 years old) were Millennials. It would be interesting to see how these Millennial teachers view digital technology. As a generation, they are often thought to possess different characteristics from their teachers and parents (Luttrell \& McGrath, 2015) but as we shall see in this report, the difference may not be very clear-cut as far as language teaching is concerned.

Figure 1 shows the responses as to whether they feel threatened by the proliferating apps and websites that help students learn English. It also shows the percentages of the responses to the question that asked them if they felt threatened by the rapidly proliferating apps and websites for language learning. As many as $1.8 \%$ said that they sometimes felt uneasy, while the other $84.5 \%$ said that they never felt worried.

Figure 2 shows the conditions which make them feel threatened in their career. 


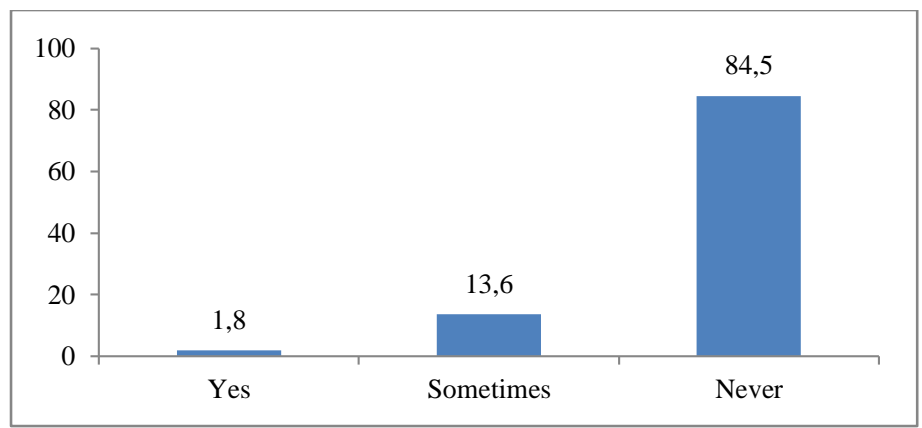

Figure 1. Percentage of respondents with their answers

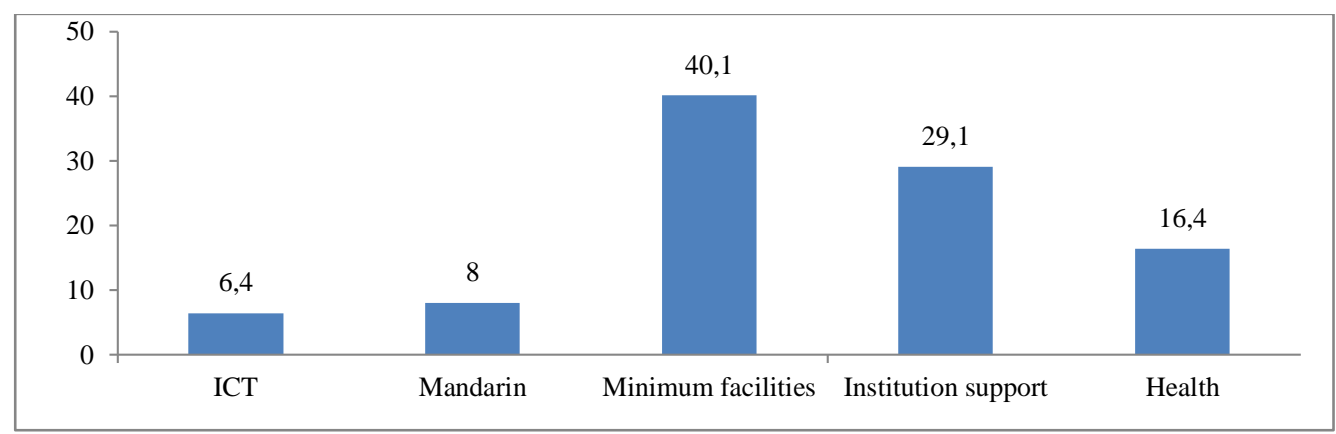

Figure 2. Conditions which teachers perceive as threats

As Figure 2 shows, only $6.4 \%$ of the respondents felt that artificial intelligence and other forms of digital advancement threatened their career. As many as $8 \%$ viewed the rise of Mandarin language as a potential threat. The majority, who made up $85.6 \%$ of the respondents, felt that none of the aforementioned conditions posed a threat to their careers. Instead, they perceived minimum facilities, institutional support, and health condition as possible threats to their career.

Figure 3 depicts the conditions they feel have assisted them in their career.
The next question asked them what have assisted them in their jobs as language teachers. As Figure 3 shows, most of the respondents, that is $70 \%$, said that they enjoy the assistance from advanced information and communication technology. The other $23.6 \%$ perceived teaching-learning facilities as vital in their jobs, and the other $11.8 \%$ felt that institutional support (including remunerations) comprised the most helpful aspect.

Figure 4 describes their degree of agreement on three statements concerning ICT and their career as language teachers.

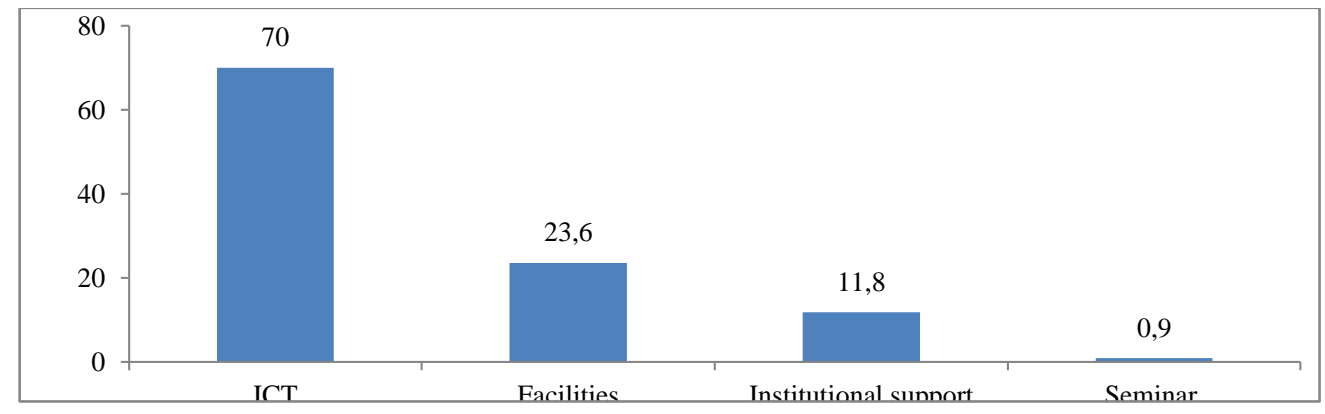

Figure 3. Conditions which teachers perceive as helpful

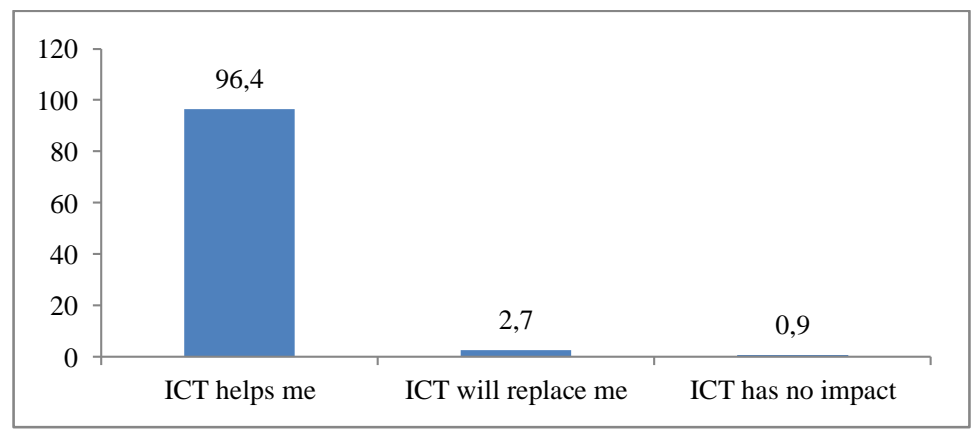

Figure 4. Respondents' statements on digital technology and their career

Copyright (C) 2018, IJAL, e-ISSN: 2502-6747, p-ISSN: 2301-9468 
The above tendency is in line with the answers to the last closed-ended item asking how the respondents viewed information and technology in their careers. As Figure 4 shows, the majority of them, $96.4 \%$, stated that they viewed it as a supportive tool.

The answers to open-ended items were transcribed and coded using thematic analysis technique. Two themes that immediately emerged from the coding were ICT as a threat to teachers and ICT as a supportive tool for teachers. The themes and the corresponding portions of data are presented in Table 2.

There is also an opinion about the lack of institutional support for the updating of hightechnology. This particular respondent said that the reluctance to provide cutting edge technology and meager incentives sometimes caused teachers to put in a minimum effort in their work.
The following section discusses some respondents' perception of ICT as a possible threat to their career.

\section{ICT as a threat}

Table 2 above shows that the reasons why the respondents perceived ICT as assistant slightly outnumber the reasons for viewing ICT as a threat. Under the theme of ICT as an assistant, respondents came up with a wide range of reasons. These reasons can further be grouped into three kinds, namely: (1) learning resources, (2) high appeal to the students, (3) communication and collaboration with other teachers, and (4) variety in teaching learning activities. Thus, they encompass a wide spectrum of teaching learning activities, covering learning materials, students, communication between teachers and between students, and the actual instructions.

Table 2. Respondents' opinion on the roles of ICT

\begin{tabular}{|c|c|}
\hline Theme & Illustrations in the data \\
\hline ICT as an assistant for teachers & $\begin{array}{l}\text { "provides a variety of learning resources". } \\
\text { "updates information and increases my expertise." } \\
\text { "facilitates blended-learning activities." } \\
\text { "gives additional references." } \\
\text { "gives options of learning resources." } \\
\text { "gives easier access to materials." } \\
\text { "appeals to the students." } \\
\text { "provides authentic materials." } \\
\text { "serves as a variety in learning activities." } \\
\text { "serves as a source for enrichment for the students" } \\
\text { "helps explain a concept." } \\
\text { "creates variety in teaching-learning process." } \\
\text { "makes teaching more interesting and challenging." } \\
\text { "helps to find teaching techniques." } \\
\text { "helps to prepare materials for lessons." } \\
\text { "keeps content updated." } \\
\text { "increases learning quality." } \\
\text { "promotes learners' autonomy." } \\
\text { "enhances communication between students and teachers." } \\
\text { "promotes more intensive communication and collaboration with other teachers." } \\
\text { "encourages students to enhance creativity, collaboration, and innovation." } \\
\text { "overcom a wide range of free downloadable learning materials." } \\
\text { "encourages paperless work environment.". }\end{array}$ \\
\hline ICT as a threat to teachers & $\begin{array}{l}\text { "when the students favor ICT more than they like the teachers." } \\
\text { "there are many applications that help students learn English and this will replace } \\
\text { teachers." } \\
\text { "when the teachers are reluctant to utilize ICT in their instructions." } \\
\text { "when the institutions do not update ICT facilities and do not offer incentives for } \\
\text { teachers for their extra effort." } \\
\text { "when teachers cannot keep up with its rapid advances." } \\
\text { "when the teachers do not improve themselves, do not learn more, and do not enhance } \\
\text { their teaching techniques or renew the lessons." } \\
\text { "translating apps will weaken students' abilities to write English on their own." } \\
\text { "encourages copy paste by students." } \\
\text { "students can obtain information from doubtful or untrustworthy sources." } \\
\text { "when some online games are not suitable for the students' native culture." } \\
\text { "inadequate qualities of human resources." } \\
\text { "students can read materials that they want to find from the web which their } \\
\text { classes/teachers fail to provide." } \\
\text { "load of administrative work and teaching and lack of funding may keep teachers from } \\
\text { upgrading their ICT skills." }\end{array}$ \\
\hline
\end{tabular}


Nevertheless, their responses under the theme of ICT as a threat also merit consideration. In essence, these responses serve as a reminder of factors that may cause ICT to turn hostile. They remind the teachers to always update their own knowledge and skills in utilizing ICT so as to prevent themselves from being replaced by the advanced digital technology. Furthermore, with their students being very adept at utilizing ICT, they should feel a heightened sense of urgency to update their knowledge and skills of using the same technology. Other worries were related to online games, load of work that prevents them from updating their ICT skills, and students who find Webbased sources to be more relevant to their needs and which the school curricula fail to meet.

For teachers of the age range from 20 to 40, keeping themselves with the latest trend of ICT may not be a difficult task because they themselves are more or less digital natives. But for teachers above 50, such undertaking may be considerably daunting. A digital gap may start to form between these senior teachers and their much younger students. Though they can afford to gain access to such technology, the senior lecturers would probably feel clumsy and even at loss to utilize fully the ICT for their teaching purposes.

Holden, Ozok, and Rada (2008) conducted a survey among forty-seven secondary education math and science teachers in one American city about their use and perceptions of technology in their lives and classrooms. The results indicated that technology was mostly used for personal instructional reasons, such as class preparation, rather than for interactions with their students inside or outside the classroom. The meager use of technology was related to time, training, and preparation. Although the teachers realized the benefit of using technology to promote students' learning experience, they were not very certain that technology was useful for improving in-class activities. It should be noted that their study took place ten years earlier than my study. Because Internet technology has been rapidly progressing since then and younger teachers have started to be more active in their career, my study would reveal a new tendency among today's language teachers.

A more recent study by Yu, Yuen and Park (2012) addressed the issue of digital divide, i.e. the different knowledge level and access to digital technology between generations. They found that essentially teachers and students had equal access to computer hardware and the Internet. However, they differed in terms of types and levels of usage of such technology. The students used Web 2.0 technologies more frequently, but rarely did they do so for educational purposes. The parents seemed to be less knowledgeable about the Web 2.0 technologies, although they were concerned about the effect of such technologies on their children's development. The teachers, meanwhile, used Web 2.0 technologies mostly for observing students' online behaviors. Thieman (2008) found in a survey among 223 preservice teachers that the most frequent acts of using technology were searching on the Internet and using word processor. The use of webpages and subject-specific software was practically zero. Since the two studies above dated almost seven and ten years ago, respectively, it is safe to conclude that the current situation may be a little different. As my survey indicates, teachers are more cognizant of the various roles that digital technology can play for the benefit of teaching-learning process. Such a leap is not uncommon because as West (2013) noted "within only two years, (2008-2010), there was a remarkable increase in teachers' use of digital technology for instructional purposes" (p. 13).

\section{Models that assist language teachers adapt to digital technology}

At the outset, it is important to relate the respondents' answers to what is called Technological Acceptance Model (TAM). As Huang, Teo, and Zhou (2017) argued, TAM manifests in two determinants, namely perceived usefulness and perceived ease of use. Perceived usefulness refers to the extent to which teachers believe that digital technology will help them accomplish their work efficiently and effectively. Perceived ease of use refers to the extent to which teachers believe that they do not have to deal with a lot of troubles and efforts in using the high technology. The two factors jointly determine one's attitude toward technology. In the light of this principle, the respondents seemed to have positive perceived usefulness and perceived ease of use. Such perception gave rise to their positive attitude toward digital technology.

One of the respondents hinted at the possibility of teachers being too slow to respond to the rapidly advancing digital technology. The inability to afford expensive technology, poor institutional support, and poor skills in exploiting features of digital technology may cause some teachers to lag behind. Soon they could be outpaced by the technological advances, while their younger students are becoming more adept at utilizing technology. The use of Google Translate and sites that could generate quick summary of texts (such as https://smmry.com/) are only two examples of how technology could help students avoid the hard work and perseverance needed to accomplish class assignments and still earn good scores.

The worry that ICT will someday pose a bigger threat to teachers' career finds grounds from the present condition described below:

From social networks to search engines, digital tools will continue to redefine literary and reshape the architecture of learning. A wide range of technological tools are already helping students learn in different ways, while permitting them to explore a much broader world of knowledge and learning. There is much more to come (Adams \& Hamm, 2017, p. 103).

Howard and Mozejko (2015) proposed three factors that determine the extent to which teachers are willing to use digital technology in their jobs: school 
culture, confidence in using technology, and beliefs about technology. Schools which tout information technology-supported learning should also promote a culture of student-centered atmosphere in their daily instructions, which in turn requires full commitment to providing the necessary infrastructure. If the teachers sense that the schools they work for do not provide support for this aspiration, they will lack strong motivation to refine their skills of teaching with digital technology. In terms of confidence, some teachers, notably those who belong to the so-called 'digital immigrants', may decide not to use high-technology for fear of not knowing how to fix technical problems that may happen. Finally, teachers' decision to utilize digital technology also hinges on their beliefs about that particular technology. Teachers who decide to use digital technology are certain that it refines the effectiveness and efficiency of their teaching and is relevant to their needs. Apparently, most of the respondents in my survey have positive beliefs about the role of digital technology in their career. Their answers to the open-ended question reflect that positive attitude. They can immediately mention various applications and websites that have evidently supported their teaching.

In another study, Labbas and Shaban (2013) argued that teachers may feel uneasy about the changing field of education because they have to prepare their students for a future they themselves can hardly describe. Worse, they see many of their students begin to emulate them in the skills of using digital technology. It seems understandable why some teachers feel jittery about today's technology-driven education. A further implication may be a situation in which the ever growing digital applications eventually replace the role of a teacher. At least one of the respondents voiced this concern, saying "there are more apps that help students learn English and they will eventually replace teachers."

$\mathrm{Li}$ (2007) reported a study on the same topic and found that among the respondents he studied, the fear of technology was apparent but not explicitly stated. When asked whether they were worried about the possibility of being replaced by high-technology, they indirectly cited reasons like time and curriculum pressure and the insufficient number of computers available. But this study was a bit dated; my study offered a newer insight into teachers' opinion about the possible impact of hightechnology on their career.

Selwyn (2010) addressed a notion that may still hold true for some teachers:

Teachers have long been described as conservative and generally resistant to change in many of their practices. . . . the majority of teachers are still felt to be cautious onlookers as opposed to a minority of enthusiastic innovators. (p. 32)

The above notion is in line with what Sipila (2011) found among Finnish primary and secondary teachers. These teachers' use of ICT was limited to informational, organizational, evaluative and lesson-planning purposes.
They have yet to utilize ICT for communicative, activating, creative, and expressive purposes.

Hockly, Dudeney and Pergrum (2014) mentioned several common perceptions among teachers about digital technology. There is a common worry that digital technology will replace teachers, face-to-faceteaching, and pedagogy. They also think that it is not suited for education. In addition, digital technology is typically perceived as suffering from delays and glitches. Teachers also think that their students know more about the technology than they do, and students want to use the technology all the time. Finally, they themselves feel they receive inadequate training to use the technology.

The authors then presented responses to those aforementioned worries about digital technology. First, they argued that although digital technology is primarily designed for purposes other than education, they can always be modified to fit educational purposes. They did not deny the possibility of digital technology sometimes breaking down, but they suggested that teachers should always have a back-up plan in the event of technological glitches. Concerning the fear that technology will replace teachers, they argued that as content and pedagogy comes first, teachers should decide the content and the instructional methods to be used before assigning their students to utilize apps, blogs, or any other digital technology. Teachers should also not worry that technology will replace conventional sessions because what is actually happening is a combination of conventional and online learning which is called blended learning. The fact that students know more technology than their teachers do is true; however, it is also equally true that the students still need teachers' guidance and instructions for utilizing their digital gadgets to enhance their learning and academic skills. Navigating the Web to find academic resources and use the information properly is one skill that teachers can teach.

Hockly, Dudeney, and Pergrum (2014) then proposed TPACK (Technological Pedagogical Content Knowledge) model to view the relationship among teachers, teaching, and technology. According to this framework, while pedagogical and content knowledge is obligatory for teachers to master, technological aspects should serve to complement rather than replace their didactic skills. In other words, technological advancement should be seen as an assistant rather than as a threatening force that would supplant human teachers in the future.

Meanwhile, there is a common view that training teachers how to integrate technology into their teaching is still important. Kurniawati, Maolida, and Anjaniputra (2018) in their recent research suggested that the socalled digital immigrant teachers should develop their digital literacy in order to be fully functional in the digital era. Kim, Foster and Cho (2017) stated that such training is effective if it takes into consideration the four principles, namely compatibility, complexity, trialability, and observability. Compatibility means that 
teachers should be able to see that the training accords with their beliefs and needs. Complexity refers to the extent of how difficult the new technology is. Trialability is the extent to which teachers can try using the technology in their work. Finally, observability is the extent to which they can see the positive outcome of such integration. In the same vein, Ackerman (2017) proposed UTAUT (Unified Theory of Acceptance and Use of Technology), which essentially posits that teachers will tend to utilize advanced technology that is easy to use, that will assist them in accomplishing their important duties, that their colleagues also use, and that enjoys support from the institutions they work for. School leaders should be aware of these factors so they know how to encourage their teachers to make the best use of digital technology.

\section{Digital applications that language teachers use}

Answering a question of what websites or digital applications they have been using for their teaching, the respondents mentioned quite a wide variety of such digital facilities. Most notably are YouTube (mentioned 19 times), BBC (mentioned 14 times), Edmodo (mentioned 8 times), Duolingo (mentioned 5 times), online dictionaries (mentioned 6 times), and VOA (mentioned 3 times). It is interesting to note that Google was mentioned 17 times, a sign that this powerful search engine serves as a portal that lead the respondents to many useful sites which meet their learning needs.

YouTube, being a versatile digital tool, is unsurprisingly the most preferred site. It caters for the three aspects mentioned above. It serves as a learning resource rich with types of lessons catering for different needs and language levels, is highly appealing to students, and constitutes a refreshing variety in the teaching-learning process. In addition to this, YouTube presents itself as a digital medium which allows people to broadcast their own achievements and records, and offers social interactivity, i.e. the active exchanges of opinions between viewers and producers (Thompson, 2011).

Likewise, Duolingo is understandably popular among the respondents, as it is in many other parts of the globe. Probably its most attractive feature is the game element embedded in the comprehension and vocabulary practices that makes language learning a fun activity (Maughan, 2016). This inclination toward game-based apps is pertinent to a recent phenomenon of informal language learning whereby learners develop their language mastery by engaging in different kinds of digital interaction that are in contrast with formal learning in a classroom (Godwin-Jones, 2018). Informal language learning is on the rise and enjoys the support of advancement in ICT, prompting language educators to consider its potential as well as face some consequences it may cause for teachers accustomed to a more formal learning.

Edmodo, which was mentioned 9 times, is indeed a versatile platform that caters for various needs in teaching and learning. Quite probably teachers of various ages favor this platform because its userfriendly features enable them to present brief lectures, assign tasks, store materials, and encourage the students to adopt a more or less personalized style of learning. Its asynchronous nature permits students to learn and do the assignments at their own pace with their own ways at places they feel most convenient. At least, two studies by Balasubramanian, Jaykumar, and Fukey (2014), and another one by Kongchan (2008) gave empirical support to these beneficial features.

BBC also enjoys popularity among the respondents. This is obviously the fruit of long development that dates back to the 1950s and was aimed to make BBC "an important new medium by means of which British approaches to the teaching of English as a foreign language could be propagated on a worldwide scale" (Smith, 2005, p. xxii). Likewise, VOA is also popular among the respondents. This site delivers graded English to suit learners' varied proficiency levels and covers a wide gamut of interests, ranging from history to science and technology (Seib, 2009). It is designed for learners of intermediate to upper-beginner level, and delivers spoken English at one third the normal speech rate. Using journalism as the basis for creating learning materials, it offers topics of wide interest that include news, business, American life, popular culture, science and economy (Tzu-Wen, 2016). The respondents clearly favor these versatile, engaging, and comprehensive websites managed by two states which so far have been largely perceived as the primary models of standard English.

It is interesting to note that apart from ICT, some respondents also addressed the possible impact of another factor, namely another foreign language. As many as $8 \%$ of the respondents were concerned about the possibility of Mandarin language replacing English as the most dominant lingua franca in the world. According to Gil (2011), there are some factors behind the rising popularity of Mandarin language. First, China has been establishing itself as a major exporter, manufacturer and consumers of goods, making it one of the most influential countries in the world; second, it learns and develops various kinds of modern technology. Along with its increasingly advanced military power, it enjoys a greater international recognition. Also, there are more schools and universities outside China which offer Chinese courses, undeniable evidence of its rising popularity. In the light of these facts, English could stand the risk of having to struggle to maintain its status as international language because of this stronger and more widespread motivation to learn Mandarin. Many English teachers, in particular, would have to face challenges not only from digital technology but also from the rising popularity of another global lingua franca.

\section{CONCLUSION}

The paper sets out to describe a profile of English teachers' perspective on the role of ICT in their career. 
Specifically, it aims to identify the things that teachers perceive as threats and whether they feel threatened by ICT. An analysis of their responses to closed and openended items of a questionnaire reveals that most of them never feel threatened by ICT. In fact, most of them see ICT as helpful for their work, and they believe that instead of replacing them as teachers, ICT will help them do their job more effectively. Inadequate facilities, institutional support, health, and the rise of Mandarin language are generally perceived to be more worrisome than ICT.

Data from the respondents' answers to the openended question revealed more or less the same idea, namely that they think ICT has been very beneficial for their work because it offers abundant learning resources, is highly appealing to students, promotes communication and collaboration with others, and encourages varied activities in the teaching-learning process.

Nevertheless, responses that voice worries over ICT also merit consideration. ICT will prove detrimental if the teachers lag behind their students in terms of skills of utilizing digital applications. Teachers are in need for constantly refining their skills in using ICT-driven facilities. Poor institutional support that otherwise could help teachers update their skills will aggravate the problem. Moreover, the advancement of ICT could proceed at an increasingly fast rate which at a certain point in the future will make language learning possible without the presence of human teachers.

To help teachers cope with the fast-changing condition of their field, some models have been proposed. TAM (Technological Acceptance Model) and UTAUT (Unified Theory of Acceptance and Use of Technology) are two frameworks that help teachers take the necessary acts in response to the rapid progress of ICT. TPACK (Technological Pedagogical Content Knowledge) is another model that helps teachers selectively focus their efforts on the content and pedagogical aspects of their lessons. All in all, teachers should not be left unguided in this volatile and sometimes unpredictable world of digital technology. Models and principles that help them discern their roles as teachers and make the necessary adjustment should always accompany them as they devote themselves to the betterment of their students.

\section{REFERENCES}

Ackerman, G. L. (2017). Strategies to increase technology acceptance. In Grassetti, M., \& Brookby, S. (Eds). Advancing next generation teacher education through digital tools and applications (pp. 1-18). Hershey, PA: IGI Global.

Adams, D., \& Hamm, M. (2017). Engaging eager and reluctant learners: STEM learning in action. Maryland: Rowman \& Littlefield.

Asnawi, M., Qismullah, Y. Y., and Rena, J. (2018). Perceptions and barriers to ICT use among English teachers in Indonesia. Teaching English with Technology, 18(1), 3 - 23.

Balasubramanian, K., Jaykumar, V., and Fukey, L. N. (2014). A study on student preference towards the use of Edmodo as a learning platform to create responsible learning environment. ProcediaSocial and Behavioral Sciences, 144, 416 - 422. doi: 10.1016/j.sbspro.2014.07.311

Bridglall, B. L. (2018). Preparing for disruption by creating future possible selves. Liberal Education, 104(1), $34-39$.

Brown, J. D. (2001). Using surveys in language programs. Cambridge: Cambridge University Press.

Driessen, B. (2017). Three ways education is being disrupted by digital technology. Digital Pulse. Retrieved 20 April 2018 from https://www.digitalpulse.pwc.com.au/three-wayseducation-disruption-digital-technology/

Gil, J. (2011). A comparison of the global status of English and Chinese: towards a new global language? English Today, 27(1), 52 -59. doi: $10.1017 / \mathrm{S} 0266078411000149$

Godwin-Jones, R. (2018). Chasing the butterfly effect: Informal language learning online as a complex system. Language Learning \& Technology, 22(2), 8-27. doi: 10125/4463

Hockly, N., Dudeney, G., \& Pergrum, M. (2014). Digital Literacies. London: Routledge.

Holden, H., Ozok, A., \& Rada, R. (2008). Technology use and acceptance in the classroom: Results from an exploratory survey study among secondary education teachers in the USA. Interactive Technology and Smart Education, 5(2), 113-134, doi: 10.1108/17415650810880772

Howard, S. K. \& Mozejko, A. (2015). Teachers: technology, change, and resistance. In Henderson, M., \& Romeo, G. (Eds.) Teaching and digital technologies: Big issues and critical questions (pp. 307 -317). Port Melbourne, Australia: Cambridge University Press.

Huang, F., Teo, T., \& Zhou, M. (2017). Understanding factors influencing English teachers in Chinese universities to teach with technology. In Ma, W. W. K., Chan, C., Tong, K., Fung, H., and Fong, C. (Eds). New ecology for education-communication $X$ learning: Selected papers from HKAECT-AECT 2017 summer international research symposium. Singapore: Springer Nature Singapore. doi: 10.1007/978-981-10-4346-8_10

Kim, J. H., Foster, A., \& Cho, M. (2017). Professional development for technology integration into differentiated math instruction. In Keengwe, J., and Bull, P. H. (Eds.). Handbook of research on transformative digital content and learning technologies (pp. 1-24). Hershey, PA: IGI Global.

Kongchan, C. (2008). How a non-digital-native teacher makes use of Edmodo. Paper presented at the International Conference ICT for Language Learning ( $5^{\text {th }}$ Edition). Florence, Italy. 
Kurniawati, N., Maolida, E. H., \& Anjaniputra, A. G. (2018). The praxis of digital literacy in the EFL classroom: Digital immigrant vs digital-native teacher. Indonesian Journal of Applied Linguistics, 8(1), 28-37. doi: 10.17509/ijal.v8i1.11459

Labbas, R., \& Shaban, A. E. (2013). Teacher development in the digital age. Teaching English with Technology, 13(3), 53-64.

Li, Q. (2007). Student and teacher views about technology: a tale of two cities? Journal of Research on Technology in Education, 39(4), 377397. doi: 10.1080/15391523.2007.10782488

Liu, H., Lin, C., Zhang, D., and Zheng, B. (2017). Chinese language teachers' perceptions of technology and instructional use of technology: A path analysis. Journal of Educational Computing Research, 56(3), 85-101. doi: $10.1177 / 0735633117708313$

Lubis, A. H. (2018). ICT integration in $21^{\text {st }}$-century Indonesian English language teaching: Myths and realities. Cakrawala Pendidikan, 37(1), 11-21. doi: $10.21831 /$ cp.v37i1.16738

Luttrell, R., \& McGrath, R. (2015). The millennial mindset: Unraveling fact from fiction. Lanham: Rowman \& Littlefield.

Maughan, P. (2016). The slacker's sanctuary. New Statesman, 145(5325), $17-18$.

Seib, P. (2009). Toward a new public diplomacy: Redirecting U.S foreign policy. New York: Palgrave Macmillan.

Selwyn, N. (2010). Schools and schooling in the digital age: A critical analysis. London: Routledge.
Sipila, K. (2011). No pain, no gain? Teachers implementing ICT in instruction. Interactive Technology and Smart Education, 8(1), 39 -51. doi: 10.1108/17415651111125504

Smith, R. C. (2005). Teaching English as a foreign language 1936-1961 foundations of ELT. London: Routledge.

Thieman, G. Y. (2008). Using technology as a tool for learning and developing 21 st century citizenship skills: An examination of the NETS and technology use by preservice teachers with their $\mathrm{K}-12$ students. Contemporary Issues in Technology and Teacher Education, 8(4), 342366.

Thompson, A. (2011). Passing strange: Shakespeare, race, and contemporary America. New York: Oxford University Press.

Tzu-Wen, S. (2016). Selected readings in trade and economics 2016 taken from VOA learning English. Readenough.net

Visuvalingam, V. (2006). A conceptual framework to explain technology acceptance of electronic negotiation utilizing software agents. (Master's thesis). University of Waterloo, Ontario, Canada.

West, D. M. (2013). Digital schools: How technology can transform education. Washington, DC: Brookings Institution Press.

Yu, M., Yuen, A. H. K., \& Park, J. (2012). Using Web 2.0 technologies: Exploring perspectives of students, teachers and parents. Interactive Technology and Smart Education, 9(4), 204 -216. doi: 10.1108/17415651211284002 